\title{
KEBIJAKAN REDAKSIONAL SURAT KABAR FLORES POS DALAM MEMPERTAHANKAN EKSISTENSI
}

\author{
Lodowik Nikodemus Kedoh \\ Magister Komunikasi Universitas Dr. Soetomo Surabaya \\ kedohjek@yahoo.co.id
}

\begin{abstract}
Flores Pos is one of the most popular and historic newspapers in the province of East Nusa Tenggara (NTT). This newspaper is very well known, accepted and made as one of the information references. Until now, Flores Pos is still present and able to survive in the midst of media competition and the development of information technology, although the appearance is still old-fashioned. This fact requires the editor of Flores Pos to determine the editorial policy of their institutions in order to be able to survive in the competition. This study aims to find out how Flores Pos editorial policy in maintaining its existence. This research uses descriptive qualitative analysis method used in this study and uses descriptive data that presents written and oral words from the subject and observable behavior. This research requires informants to obtain data and facts from a phenomenon. The object of this research is the Flores Pos newspaper. For data collection using direct observation, interviews, and literature studies. While at the stage of data analysis it is carried out through data collection, reducing data, presenting data and making conclusions. The findings in the study show that, 1) Editor of Flores Pos has the concept of editorial policy that has been designed and used for a long period of time. 2) In its reporting, Flores Pos chose to accommodate the interests of the community. 3) In maintaining its existence, the editor of Flores Pos seeks to always prioritize the power of its reporting and choose not to converge media. 4) Flores Pos adheres to its idealism and vision and mission as guidelines for internal policies that are umbrella in the Press Law and Journalistic Code of Ethics.
\end{abstract}

Keywords: editorial policy, newspaper content, existence.

\begin{abstract}
Abstrak
Flores Pos merupakan salah satu surat kabar yang populer dan bersejarah di Provinsi Nusa Tenggara Timur (NTT). Surat kabar ini sudah sangat dikenal, diterima dan dijadikan salah satu rujukan informasi. Hingga saat ini, Flores Pos tetap hadir dan mampu bertahan di tengah persaingan media dan perkembangan teknologi informasi, walaupun tampilannya masih bergaya lama. Kenyataan ini menuntut pihak redaksi Flores Pos untuk menentukan kebijakan redaksional institusi mereka agar mampu bertahan dalam persaingan tersebut. Penelitian ini bertujuan untuk mengetahui bagaimana kebijakan redaksional Flores Pos dalam mempertahankan eksistensinya. Penelitian ini menggunakan metode analisis deskriptif kualitatif digunakan pada penelitian ini serta menggunakan data deskriptif yang menyajikan kata-kata tertulis serta lisan dari subjek dan perilaku yang dapat diamati. Penelitian ini memerlukan informan guna mendapatkan data serta fakta dari sebuah fenomena. Obyek penelitian ini adalah surat kabar Flores Pos. Untuk pengumpulan data menggunakan pengamatan langsung, wawancara, serta studi kepustakaan. Sedangkan pada tahapan analisis
\end{abstract}


data dijalankan melalui pengumpulan data, mereduksi data, penyajian data dan membuat kesimpulan. Temuan dalam penelitian menunjukkan bahwa, 1) Redaksi Flores Pos telah memiliki konsep kebijakan redaksional yang telah dirancang dan digunakan untuk jangka waktu yang panjang. 2) Dalam pemberitaannya, Flores Pos memilih untuk mengakomodasi kepentingan masyarakat. 3) Dalam menjaga eksistensinya, redaksi Flores Pos berusaha selalu mengutamakan kekuatan pemberitaannya dan memilih untuk belum melakukan konvergensi media. 4) Flores Pos memegang teguh idealisme dan visi dan misinya yang sebagai pedoman kebijakan internal yang berpayung pada Undang-Undang Pers dan Kode Etik Jurnalistik.

Kata kunci: kebijakan redaksional, isi surat kabar, eksistensi.

\section{PENDAHULUAN}

Saat ini masyarakat menyaksikan pesatnya perkembangan teknologi di bidang informasi dan komunikasi. Perkembangan teknologi sendiri juga dibarengi dengan sesuatu yang sifatnya update secara berkelanjutan dan akan disusul dengan teknologi lainnya. Hal ini didukung kemudahan akses internet yang semakin meningkat di setiap Negara. Tidak dapat disangkal bahwa kebutuhan manusia di jaman digital adalah internet. Berkembangnya era new media yang ditandai dengan semakin maraknya media online telah menyebabkan semakin tergerusnya industri media cetak seperti surat kabar dan majalah.

Perubahan yang dialami media cetak kea rah media yang berpijak pada proses digital atau online pastinya akan menimbulkan sebuah pertanyaan tentang bagaimana kondisi media cetak di tengahtengah masyarakat baik berkaitan dengan perannya serta eksistensinya. Tidak dapat disangkal bahwa teknologi mampu memberikan kemudahan bagi masyarakat dalam hal memperoleh informasi. Saat ini, melalui media digital, informasi yang dibutuhkan masyarakat dapat diperoleh dalam waktu yang relatif cepat. Alasan inilah yang menjadikan media cetak kemudian beralih ke digital untuk menyajikan lembaran beritanya.

Keunggulan surat kabar dalam pemberitaan merupakan sesuatu yang patut dipertahankan, dalam hal ini adalah bagian keredaksian yang memiliki peran penting dalam menentukan nilai berita serta kelayakan sebuah berita untuk dimuat atau tidak. Bagian redaksi merupakan bagian penting dalam menentukan kebijakan redaksional sebuah surat kabar agar produk berita yang diberikan kepada khalayak mampu memberikan nilai manfaat sesuai dengan fungsi dari surat kabar itu sendiri.

Sebuah kebijakan dari redaksi atau yang disebut sebagai kebijakan redaksional adalah sebuah pedoman yang tersirat serta dijadikan acuan bagi redaksi sebuah surat kabar dalam mengelola penerbitannya. Hal tersebut juga dipahami sebagai kaidah dan sebagai pijakan awal dari setiap langkah operasional dalam pemberitaan. Pada dunia jurnalisme, redaktur identik sebagai penjaga gawang atau sering disebut dengan istilah gatekeeper.Kebijakan redaksional memang diperlukan untuk menyikapi lebih jauh tentang suatu peristiwa. Hal ini dikarenakan pada alam dunia pemberitaan yang terpenting tidak saja peristiwanya tetapi juga bagaimana seseorang bersikap terhadap peristiwa itu sendiri. 
Untuk menyikapi suatu peristiwa dalam dunia pemberitaan, kebijakan redaksi itu menjadi penting. Yang penting bukan hanya sebuah peristiwa, tetapi juga bagaimana sikap terhadap peristiwa tersebut. Apabila media massa tidak memiliki kebijakan redaksi, dapat dipastikan beritanya tidak akan konsisten. Hal ini disebabkan media tersebut tidak memiliki pendirian dalam memberitakan suatu peristiwa. Dalam hal ini media massa menjadi seperti keranjang sampah yang mampu memuat apa saja. Inkonsistensi akan kelihatan pada sebuah berita yang selalu mengalami perubahan, bahkan kadangkala saling bertentangan. Media massa yang beritanya tidak konsisiten tersebut seakan itu tidak akan mendapat kredibilitas yang tinggi di hadapan khalayak. Jika dipahami lebih lanjut bahwa besar tidaknya pengaruh suatu media massa tidak hanya hanya dilihat pada jumlah oplah atau banyaknya pendengar serta penonton, tetapi yang tidak kalah penting adalah kredibilitasnya (Tebba, 2005).

Rubrikasi pada Flores Pos cukup unik dan berbeda dibandingkan surat kabar lainnya. Secara umum, surat kabar lain biasanya menggunakan rubrikasi berdasarkan topik (topic based rubrication), sedangkan Flores Pos dilihat menerapkan rubrikasi berdasarkan daerah (distric based rubrication). Tampilan dan cetakan harian umum Flores Pos hingga saat ini masih bergaya lama atau old style (hitam putih) namun tetap bertahan dan eksis, inilah yang membuatnya berbeda dari surat kabal lokal lainnya di NTT.

Perkembangan teknologi new media memang tidak lagi dapat dipungkiri, hal tersebut merupakan tantangan bagi media konvensiaonal seperti Flores Pos dalam mempertahankan eksisitensinya. Kondisi ekonomi masyarakat NTT yang relatif rendah, ditambah dengan kondisi geografis yang masih sulit dijangkau, adalah merupakan tantangan bagi surat kabar Flores Pos dalam mengemban misi jurnalistiknya bagi masyarakat NTT, agar keberadaanya sebagai surat kabar yang matang dalam hal usia dan pemberitaannya, tetap terjaga di tengahtengah masyarakat NTT.

Tantangan lain bagi surat kabar lokal untuk mempertahankan kelangsungan hidupnya adalah bagaimana landasan idiil yang bagus didukung oleh landasan komersil yang meliputi sistem manajemen redaksional dan finansial serta tenaga profesional yang handal. Sebab idealisme tanpa didukung oleh kemampuan mengelola manajemen dan finansial yang kuat, sebuah surat kabar lokal akan kehilangan daya kekuatan untuk menembus sampai ke pelosok daerah terpencil (Gobang, 2012).

Penelitian ini bermaksud untuk menggali tentang kebijakan redaksional yang diambil oleh Harian Umum Flores Pos dalam memelihara eksistensinya, sehingga mampu menjaga dan mempertahankan eksistensinya di tengah perkembangan teknologi informasi dan kompetisi media yang terus berlangsung baik dalam skala lokal maupun nasional.

\section{PEMBAHASAN}

Harian Umum Flores Pos memiliki kebijakan dalam hal memproduksi pemberitaan pada surat kabar tersebut. Secara garis besar redaksi Flores Pos berpayung atau berkiblat pada Undang- 
Undang Pers dan Kode Etik Jurnalistik serta fungsi utama media massa bagi masyarakat.

Selain itu redaksi Flores Pos juga memiliki kebijakan internal yang berkaitan dengan pemberitaan yakni berpegang teguh pada visi dari lembaga tersebut yakni menegakkan kebenaran, keadilan, perdamaian, dan keutuhan ciptaan (pro Justice, Peace, and Integrity of Creation/JPIC). Perwujudan dari visi tersebut dituangkan dalam beberapa kebijakan sebagai berikut:

1. Isi berita Flores Pos harus mampu mendidik dan mengarahkan masyarakat agar tahu dan memahami bagaimanakah pemberitaan media yang baik dan benar.

2. Berita yang dimuat Flores Pos harus memiliki

keseimbangan informasi/memiliki dua narasumber atau narasumber dari dua pihak.

3. Nara sumber dalam berita wajib dicantumkan nama dan identitas karena Flores Pos tidak menggunakan nara sumber no name.

4. Pembagian rubrik atau rubrikasi surat kabar dibuat berdasarkan wilayah kabupaten yang ada di NTT khususnya di Flores dan Lembata, dan dipadu dengan rubrik lainnya. Secara psikologis, pembacaawalnya pasti ingin mengetahui berita yang dekat dengan dirinya, bisa tentang daerahnya atau juga orang-orang yang dikenal.

5. Berita Flores Pos harus kritis mengkoreksi dan lugas apa adanya, sejalan dengan tujuan utama dari visi yang diemban yakni membela dan memperjuangkan orang kecil dan tertindas.
6. Wartawan Flores Pos wajib mencantumkan nama dan nomor ponsel pada berita yang ditulisnya, hal ini bertujuan agar mendidik para wartawan Flores Pos agar bertanggungjwab terhadap informasi yang diberikan(Wawancara dengan Steph Tupeng Witin, Pemimpin Redaksi Flores Pos, pada Sabtu, 29 Juli 2017).

Flores Pos memiliki keyakinan yang kuat bahwa media cetak akan tetap bertahan sebab proses menghasilkan berita pada media cetak ditempuh dengan langkah yang cukup panjang dan terorganisir sehingga menghasilkan berita dengan fakta yang melekat. "Publik akan dididik tentang media yang benar. Saat Flores Pos menulis berita tentang seseorang, maka Flores Pos merefleksi dirinya", lanjut Steph Tupeng Witin (Wawancara dengan Steph Tupeng Witin, Pemimpin Redaksi Flores Pos, pada Sabtu, 29 Juli 2017).

Flores Pos belum melakukan konvergensi media karena sejak awal mereka sudah mengantisipasi akan hadirnya berita atau informasi palsu/tidak benar, yang kini banyak bermunculan di media on line atau yang lebih dikenal dengan Hoax. Berita on line lebih mengejar aktualitas tanpa memperhatikan isi atau konten berita yang dipublikasikan, karena proses menghasilakan berita tersebut sangat instant sedangkan masyarakat atau pembaca yang cerdas adalah yang mengutamakan isi dan nilai dari sebuah berita. Oleh karena itu Flores Pos yakin bahwa dalam bentuk media cetak, berita yang dipublikasikan akan diserap dengan kuat oleh publik karena berita media cetak memiliki gambaran 
yang utuh tentang suatu peristiwa (Wawancara dengan Steph Tupeng Witin, Pemimpin Redaksi Flores Pos, pada Sabtu, 29 Juli 2017).

Harian Umum Flores Pos mengusung visi menegakkan kebenaran, keadilan, perdamaian, dan keutuhan ciptaan (pro justice, peace, and integrity of creation/JPIC), diimplementasikan melalui kebijakan redaksi terhadap pemberitaan. Berbagai persoalan yang dianggap menindas ataupun memperdaya masyarakat kecil akan diliput dan dituangkan dalam pemberitaan, seperti berita tentang korupsi, tentang penolakan pertambangan, tentang kurangnya perhatian pemerintah, dan sebagainya. Selain menyuarakan tentang kritik dan koreksi, Flores Pos juga memberitakan tentang fakta atau peristiwa yang mengapresiasi segala upaya dalam membangun dan memperjuangkan masyarakat, seperti berita tentang kemajuan pembangunan yang dilaksanakan oleh pemerintah daerah serta pembelaan hukum bagi kaum yang tertindas.

Kebijakan redaksi Flores Pos sejalan dengan fungsi surat kabar dalam mendidik publik melalui pemberitaan yang benar yakni tertuang dalam misi Flores Pos, yaitu: mengembangkan dialog profetis dengan orang miskin dan tertindas (preferential option for the poor), dengan masyarakat yang beragama lain (lintas agama), dengan masyarakat berkebudayaan lain (lintas budaya), dan dengan masyarakat berideologi lain. Bagi Flores Pos, berita bukan sebagai sebuah komoditas ekonomi, melainkan sebuah pelaksanaan misi. Pertimbangan pada visi dan misi untuk menyeleksi berita yang akan dimuat menegaskan fokus perhatian redaksi bukan pada tujuan keuntungan finansial.

Dari berbagai kriteria kelayakan berita, Flores Pos lebih cenderung pada kriteria kedekatan atau proximity, dengan tidak mengesampingkan kriteria lainnya.Kebijakan ini sejalan dengan visi Flores Pos itu sendiri, serta melihat pada sisi geografis dan psikologis dari kalangan pembaca Flores Pos. Telaah terhadap kedekatakan geografis lebih mengarah pada suatu peristiwa atau berita yang terjadi di sekitar dan dekat dengan lingkungan tempat tingal. Jika peristiwa tersebut semakin dekat dengan tempat domisili kita, yang terjadi adalah seseorang bisa semakin terusik dan kemudian memunculkan ketertarikan untuk mengetahui, menyimak serta mengikutinya. Sedangkan kedekatan psikologis memang lebih banyak ditentukan atau dipengaruhi oleh tingkat keterikatan pikiran dari seseorang, kemudian ada perasaan atau kejiwaan seseorang yang dekat dengan suatu objek peristiwa atau berita. Hal ini dituangkan oleh redaksi Flores Pos dalam bentuk rubrikasi berita pada Harian Umum Flores Pos yang menggunakan nama setiap Kabupaten di Flores dan Lembata sebagai nama rubrik berita pada halaman surat kabarnya, dengan demikian setiap pembaca di daerahnya masing-masing tentu pertama-tama akan mencari tahu atau membaca berita atau informasi apa saja yang terjadi daerahnya, pada halaman yang tentu saja sudah dihafal oleh mereka. Secara psikologis, pembaca Flores Pos juga akan berusaha mencari berita yang sedang aktual di daerahnya, apalagi berita tersebut berkaitan langsung dengan 
kelompok, masyarakat, sanak saudara, ataupun orang yang dikenalnya. Hal inilah yang memperkuat kedekatan Flores Pos dengan masyarakat di daerahnya.

$$
\text { Menghadapi perkembangan }
$$
teknologi informasi saat ini, berbagai media cetak/surat kabar telah berkonvergensi dalam bentuk online guna bersaing dalam memperoleh keuntungan finansial untuk menghidupi medianya. Sayangnya, banyak pula media massa yang mengesampingkan fungsi dan tugas utamanya seperti yang tertuang dalam fungsi pers, serta Undang-Undang dan Kode Etik Jurnalistik yang berlaku. Hal ini tentu saja berakibat buruk bagi masyarakat sebagai konsumen yang harus diutamakan, sebab keberlangsungan dan eksistensi sebuah media bergantung pada penilaian publik terhadap media tersebut. Apakah publik memberikan penilaianyang baik atau kurang baik, hal itulah yang akan membentuk citra dari sebuah media massa dalam hal ini surat kabar.

\section{PENUTUP}

\section{Simpulan dan Saran}

Harian Umum Flores telah
menerapkan berbagai kebijakan
redaksional yang bertujuan untuk
mendidik dan membentuk masyarakat
informasi yang paham tentang media.
Kebijakan redaksional tersebut dijalankan
dengan berpayung pada Undang-Undang
Pers dan Kode Etik Jurnalistik yang
berlaku di Indonesia, serta diselaraskan
dengan visi dari Flores Pos itu sendiri
yakni menegakkan kebenaran, keadilan,
perdamaian, dan keutuhan ciptaan (pro
justice, peace, and integrity of

creation/JPIC) serta misi dari Flores Pos yakni mengembangkan dialog profetis dengan orang miskin dan tertindas (preferential option for the poor), dengan masyarakat yang beragama lain (lintas agama), dengan masyarakat yang berkebudayaan lain (lintas budaya), dan dengan masyarakat berideologi lain.

Kebijakan redaksional Flores

Pos terimplementasi dalam bentuk pemberitaan serta keteguhannya pada prinsip kelayakan sebuah berita, bukan pada aktualitas sebuah berita yang instant dan tidak dapat dipertanggungjawabkan dan hanya menghasilkan hoax.Kebijakan inilah yang membuat redaksi Flores Pos belum memutuskan untuk terjun langsung ke dalam konvergensi media.Keteguhan prinsip dalam kebijakan redaksi yang dijalankan Flores Pos ini membuktikan bahwa jenis jurnalisme yang dijalankan oleh Flores Pos adalah Crusade Journalism yaknijurnalistik yang memperjuangkan nilai-nilai kebenaran.Nilai-nilai kebenaran inilah yang membentuk citra Flores Pos di mata masyarakat informasi, sehingga eksistensinya masih terjaga sampai saat ini.

\section{DAFTAR PUSTAKA}

Abidin, Zainal. 2007. Analisis Eksistensial, Sebuah Pendekatan Alternatif untuk Psikologi dan Psikiatri. Jakarta: Raja Grafindo Persada.

Djuroto, Totok. 2004. Manajemen Penerbitan Pers. Bandung: PT. Remaja Rosdakarya. 
Effendy, Onong Uchjana. 1993. Ilmu, Teori \& Filsafat Komunikasi. Bandung: PT. Citra Aditya Bakti.

Gobang, JKGD. 2012. Media dan Realitas Sosial. Maumere: Penerbit Ledalero

Junedi, Fajar. 2014. Manajemen Media Massa. Yogyakarta: Buku Litera.

Junaidi, Kurniawan. 1991. Ensiklopedi Pers Indonesia. Jakarta: Gramedia.

Moleong, Lexy J. 2016. Metodologi Penelitian Kualitatif Edisi Revisi (Cetakan ke 35). Bandung: PT. Remaja Rosdakarya.

Rivers, William L, Jay W. Jensen \& Theodore Peterson. 2012. Media Massa \& Masyarakat Modern.(Edisi Kedua Cetakan ke 4). Jakarta: Kencana Prenada Media Group.

Romli, Asep Syamsul M. 2005. Jurnalistik Praktis Untuk Pemula Edisi Revisi. Bandung: PT. Remaja Rosdakarya.
Siregar, Ashadi dan Rondang Pasaribu. 2000. Bagaimana Mengelola Media Korporasi-Organisasi. Yogyakarta: Penerbit Kanisius.

Sugiyono. 2016. Metode Penelitian Kuantitatif, Kualitatif dan $R \& D$ (Cetakan ke 23). Bandung: Alfabeta.

Sumadiria, A.S Haris. 2016. Jurnalistik Indonesia Menulis Berita dan Feature (Cetakan ke 6). Bandung: PT. Remaja Rosdakarya.

Tebba, Sudirman. 2005. Jurnalistik Baru. Ciputat: Penerbit Kalam Indonesia.

Tim Penyusun Kamus Pusat Bahasa. 2008. Kamus Bahasa Indonesia. Jakarta: Pusat Bahasa.

Sumber lain :

Flores Pos edisi 5 Januari 2016

Flores Pos edisi 26 Juli 2017

Flores Pos edisi 27 Juli 207 